\title{
NICKI MINAJ'S COMMENTS IN AMERICAN IDOL SEASON 12: AN ANALYSIS OF WOMEN'S LANGUAGE FEATURES
}

\author{
Diana Chandra and Made Frida Yulia \\ Sanata Dharma University, Yogyakarta \\ diana_chandra@ymail.com and frida@usd.ac.id \\ DOI: https://doi.org/10.24071/ijhs.2018.010204
}

received 15 September 2017; revised 3 December 2017; accepted 11 February 2018

\begin{abstract}
It is commonly believed that women speak differently from men. They carry certain features which are distinctive in their speech (Lakoff, 2004). However, some women are found to speak differently from women's speech in general. This phenomenon is reflected in the use of language by Nicki Minaj, one of the judges of American Idol Season 12, whose speech stands out above the rest of the other women. The study investigates Nicki Minaj's comments in American Idol Season 12 in terms of women's language features. It focuses on two issues, namely how the language used by Nicki Minaj in American Idol Season 12 conforms to women's language features and what possible factors cause the absence of women's language features in Nicki Minaj's comments to the contestants of American Idol Season 12. To find answers to the two questions, document analysis is employed, in which seven videos of live performances taken from American Idol Season 12 are examined. Meanwhile, Lakoff's theory of women's language features is employed as the guidelines to analyse the data. The findings reveal that the features characterizing women's language which appear in Nicki Minaj's comments are intensifier, emphatic stress, filler, rising intonation, and lexical hedge. The remaining features do not appear in her speech; they are tag question, 'empty' adjective, precise colour term, 'hypercorrect' grammar, 'superpolite' form, and avoidance of strong swear words. The absence of these features can be accounted for by four possible factors. They are father's speech, ethnicity, community of practice, and different social psychological perceptions.
\end{abstract}

Keywords: women's language, women's language features, Nicki Minaj, American Idol

\section{Introduction}

One's sex is reflected through his or her language. This claim is strengthened by a theory from Lakoff about women's language. This theory shows the way women's speech differs from men's speech, which is characterised by women's language features (Lakoff, 2004, p. 42). In addition, Kress and Hodge (1979) describe that language, as a social phenomenon, reflects not only the gender but also the social attitudes towards men and women. This is to say that social change and language change are mutually reinforcing (Kress \& Hodge, 1984, p. 42). Changes that take place in society will also reflect the language change. For example, one of the judges on American Idol Season 
12, Nicki Minaj, shows significant differences compared to the way the typical women speak. This phenomenon sparks an interest for further analysis. Two research questions are formulated, namely: (1) How does the language used by Nicki Minaj on American Idol Season 12 conform to women's language features? and (2) What are the possible factors that cause the absence of women's language features in Nicki Minaj's comments to the contestants of American Idol Season 12?

\section{Women's Language}

There is a stereotype that men tend to maintain their masculinity within the language which is used while women tend to maintain their femininity. Therefore, several different features are applied by them to keep their identities. Both, men and women, have their own purposes to keep applying the features. For instance, most women will use a number of linguistic features which reinforce their subordinate status (Holmes, 2008, p. 296). Through these features, they expect to be heard by the addressee.

According to Lakoff (1975), there are some linguistic features which are used more often by women than by men to express the uncertainty and lack of confidence. These features are labelled as women's language, including lexical hedge or filler, intensifier, emphatic stress, tag questions, rising intonation on declaratives, 'empty' adjectives, precise colour terms, 'hypercorrect' grammar, 'superpolite' form, and avoidance of strong swear words (as cited in Holmes, 2008, pp. 297-298).

\section{Possible Factors that Cause the Absence of Women's Language Features}

There are some possible factors that cause the absence of women's language features. They are elaborated as follows.

\section{Father's Speech}

Parents' role is important in child's language development because children firstly interact with their parents. Engle (1979) highlights the way of every parent in delivering their speech to their children is different. Mother appears to be more sensitive to her child, while father is less polite and more insensitive (Engle, 1979, p. 92). Furthermore, father's tends to use more jocular terms, but insulting, to address a son (Gleason \& Perlmann, 1985, pp. 90-91). As a result, the insulting term will not only turn out to encourage bad speech for the son, but also the daughter.

\section{Ethnicity}

Holmes (2008) points out that there are linguistic features to a person's ethnicity and these features reflect the regular interactions people have. It means that the language that is used also reflects the group's identity (p. 184). Thus, the cause of language problem experienced by the children might be from the regular interaction of particular ethnic groups in which the speakers do not really pay attention to the right form of a language. For instance, the Black English community has language disadvantages since they are historically a minority group, in which violence often exists and diversity among the group is intolerable (Kolack as cited in Edwards, 1985, pp. 143-144).

\section{Community of Practice}

Wardaugh (2006, p.127) defines community of practice as "...at the same time its members and what its members are doing to make them a community: a group of workers in a factory, an extended family, an adolescent gang, a woman's fitness group, a classroom, etc." Community of practice is also known by children as well as ethnic 
group. Parents may be wondering why children can swear, joke or insult whereas they never introduce them to such words. Gleason and Perlmann (1985) suggest that there are certain ways of speaking which are only acquired from peers and cannot be obtained from parents. If the children do not master or use the register current in their group, they will be rejected. Feeling rejected by the peers will turn to psychological consequences. Thus, children try to avoid rejection as much as possible. It can make the children insist on using the terms everytime and everywhere (Gleason \& Perlmann, 1985, pp. 93-94).

\section{Uneducated Background}

Inevitably, education at school is needed by parents to support the child's development, including language. Based on Edwards (1979), traditionally, the school takes the important role as a supporter of 'proper' language to use. It helps the children to develop their language better by introducing the standard form of language which is accepted by the dominant mainstream (as cited in Edwards, 1985, pp. 132). Therefore, children whose parents are not able to afford education for them might lose their chance to acquire more standard language form.

\section{Different Social-Psychological Perceptions}

Gleason and Perlmann (1985) also state that a social-psychological perception aims not only to describe how a language is used for appropriate communication in different social situations, but also how it is used to establish and define someone's personality characteristics (Gleason \& Perlmann, 1985, p. 95). The one who has socialpsychological perceptions which are accepted by dominant mainstream is said to be able to use language for appropriate communication and have good personality characteristics. Meanwhile, the one who has different social-psychological perspections which are not accepted by the dominant mainstream is said to be not able to use language appropriately. Being not able to use language for appropriate communication means having bad personality characteristics.

\section{The Biography of Nicki Minaj}

Based on the book entitled Nicki Minaj Biography (2012), Onika Tanya Maraj, henceforth known as Nicky Minaj, was born to father, Omar Maraj and mother, Carol Maraj, who were of Afro and Indo-Trinidadian descent. Minaj spent her life with her father, who was a severe drug addict with a long history of violence. Minaj had a very troubled childhood when she lived with her father (Good, 2012, p. 4). Everytime her parents had a crack, her father would yell and curse a lot and it really made Minaj feel very nervous and afraid (Holloway, 2012, pp. 6-7). Since then, Minaj became traumatic and was determined to change her mother's life to be better.

She enrolled herself to La Guardia High School of Music and Art and started to learn acting. In that high school, she felt weird because almost all of the students spoke with their British accent. Yet, her White friends loved the way she called them in Black accents. In addition to acting, Minaj also had an interest in singing. She once took on backup singing roles for local New York City rappers and began writing her own material (Holloway, 2012, pp. 8-9). She also added some sexual lyrics in her songs which included a lot of vulgar and curse words to give women chance to control over their own lives and not let the stereotype, created by men, control them (Good, 2012, p. 3). After successfully winning many music awards, Minaj became so popular that she was chosen to be a judge on American Idol. 


\section{Method}

To answer the first research question, document analysis is identified as the appropriate method in conducting the research whereby the data are Nicki Minaj's comments collected from the transcripts of the seven videos. Discourse analysis is also considered since the situation where Nicki Minaj commented spontaneously on a live show is relevant to what is to be studied. Next, to answer the second research question, the connection between the answer to the first research question, specifically the absence of some features, to the possible factors that cause the absence of women's language features is investigated. The biography of Nicki Minaj is also taken into consideration to support the analysis.

\section{Findings and Discussion}

The following discussion presents the data analysis related to the two research questions posed earlier.

\section{The Conformity of the Language Used by Nicki Minaj to Women's Language Features}

Seven videos of Nicki Minaj on American Idol Season 12 were used as the data sources. Then, the data were analysed by using a checklist derived from Lakoff's theory of women's language features which becomes the reference of analysis. The checklist includes filler, lexical hedge, tag question, rising intonation, 'empty' adjective, precise colour term, intensifier, 'hypercorrect' grammar, 'superpolite' form, avoidance of strong swear word, and emphatic stress. The features are presented in Table 1 along with their number of occurrences in Nicki Minaj's comments as well as the percentages.

\section{Table 1: Women's Language Features in Nicki Minaj's Comments}

\begin{tabular}{clcc}
\hline No & \multicolumn{1}{c}{ Women's Language Features } & $\begin{array}{c}\text { The Number } \\
\text { of Occurrences }\end{array}$ & Percentage (\%) \\
1. & Fillers & 10 & 22.73 \\
2. & Lexical Hedge & 2 & 4.55 \\
3. & Tag Question & 0 & 0 \\
4. & Rising Intonation & 4 & 9.09 \\
5. & 'Empty' Adjective & 0 & 0 \\
6. & Precise Colour Term & 0 & 0 \\
7. & Intensifier & 16 & 36.36 \\
8. & 'Hypercorrect' Grammar & 0 & 0 \\
9. & 'Superpolite' Form & 0 & 0 \\
10. & Avoidance of Strong Swear Word & 0 & 0 \\
11. & Emphatic Stress & 12 & 27.27 \\
\multicolumn{2}{r}{ Total } & $\mathbf{4 4}$ & $\mathbf{1 0 0}$ \\
\hline
\end{tabular}


From Table 1 it is clearly seen that out of eleven features of Lakoff's women's language features, there were only five which appeared in Nicki Minaj's comments. Ordered on the basis of frequency, they were intensifier $(36.36 \%)$, emphatic stress $(27.27 \%)$, fillers $(22.73 \%)$, rising intonation $(9.09 \%)$, and lexical hedge $(4.55 \%)$. Minaj used intensifier for anticipation that the audience might remain unconvinced with her comments. In addition to the message, this feature was also used to strengthen Minaj's feeling towards all of the performances. Some examples from the data were:

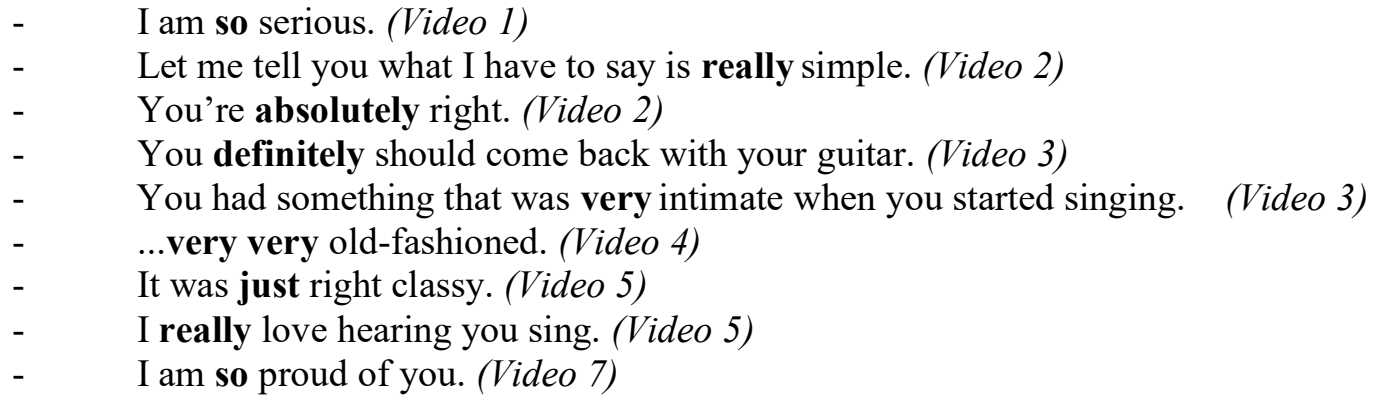

Next, Nicki Minaj employed emphatic stresses in her comments as boosting devices. Women boost the force of their utterances because they want to be heard or paid attention to (Lakoff, 2004, p. 81). Thus, Minaj did it just like what common women do. This booster expressed Minaj's lack of confidence whether she would be heard or not. Yet, the use of this booster also presented another side of Nicki Minaj. It showed that she was a kind of confident person who did not hesitate to emphasize what was in her mind in front of many people. She said, for example:

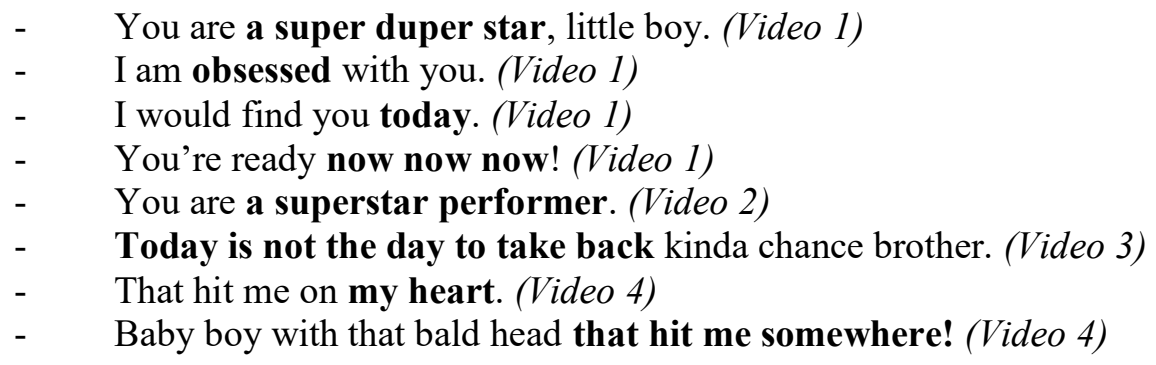

Fillers were also dominant in Minaj's speech. She made a lot of meaningless particles which did not alter the idea of her comments. It happened because she was lack of confidence on how exactly she had to convey her comments. She seemed to reduce the force of her comments to avoid the wrong statement. For instance, she remarked:

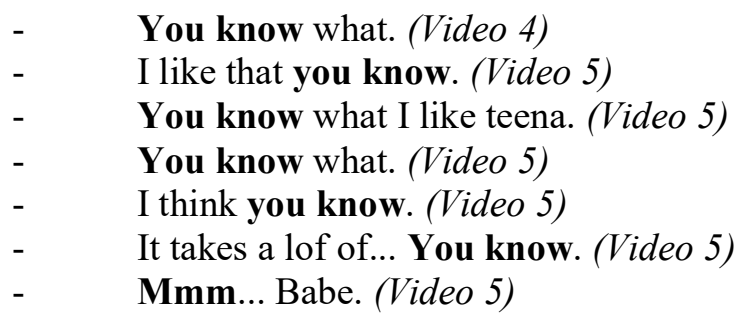


$\begin{array}{ll}\text { - } & \text { Hello Harry. Mmm (Video 6) } \\ \text { - } & \text { And } \mathbf{m m m} \text {, like buttermilk waffles (Video 6) }\end{array}$

The use of rising intonation at the end of interrogatives is not similar to declaratives. It sounds less neutral, but potentially informative since the addressee feels "violated" by the use of rising intonation on declaratives. Yet, the use of rising intonation on Minaj's comments was merely her responses towards the contestants' performances. She used this feature to emphasise the significant word to be perceived instead of seeking for the accuracy of her comments or confirmation from the others. The examples from the data were:

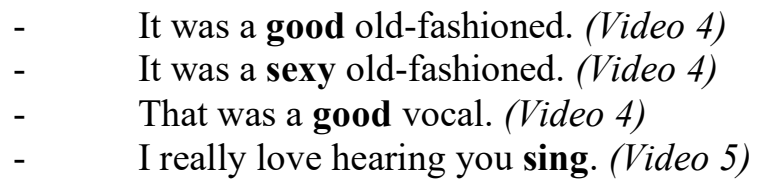

Prefacing declaration was the specific lexical hedge Minaj used in her comments. In addition, Lakoff (2004) believes that many women use this feature as their protection for not overstepping their rights by making a certain statement (p.79). Yet, Minaj appeared to be not afraid of overstepping her rights. The occurrence of this feature was merely her feeling of surprise towards the performance. Another reason was because she always seemed confident with all of her comments. As a result, her comments often sounded controversial. Minaj, for instance, said:

\section{- $\quad$ I think you know (Video 5) \\ - $\quad$ I guess learning. (Video 5)}

\section{The Possible Factors that Cause the Absence of Women's Language Featues in Nicki Minaj's Comments}

To answer the second research question, the connection between the answer to the first research question and the possible factors causing the absence of women's language features was analysed, interpreted and put into a comprehensive report by providing plausible explanation about the connection. From the analysis, it was unveiled that father's speech, ethnicity, community of practice, and different social-psychological perceptions were the possible factors that caused the absence of women's language features in Nicki Minaj's comments.

\section{Father's Speech}

When Minaj was young, her father already signed a bad routine to her, such as the use of curse words. She was used to listening to those words when her parents were arguing at each other. Certainly, it was not good for little Minaj's development, especially the development of her language. Minaj had to build it by passing through that sort of bad childhood. The result could be seen from her comments which consisted of strong swear words. By all means, Minaj also increased the number of strong swear words used by women and it was caused by her father's speech. 


\section{Ethnicity}

Language is used to reflect the group's identity (Holmes, 2008). In a similar vein, the way Minaj used the language also signaled her identity. As part of Black people, Minaj attempted to show her identity towards the language she used. It could be seen from her comments which were straightforward without any intention from her to weaken the meaning. It seems that she revealed all of her thoughts explicitly without considering whether they hurt someone's feeling or not. This possibly happened since maintaining a good relationship with other people was not an important matter for her because there was no tolerance for diversity among her ethnic group. Her behavior supported Kolack's claim (as cited in Edwards, 1985) that language disadvantages occurs in minority group whereby diversity among the group is not tolerated. Thus, she did not use tag questions to let the contestant participate on her comments or soften them.

Besides, she never employed 'empty' adjective in her comments though this adjective sounds good. Again, as a Black, she seemed to have no idea in her mind to take it into account. Since Black English community was historically put as the minority group, she also had a language disadvantage. Her language was visibly different from Standard English form, which became her symbolic way to show her identity.

\section{Community of Practice}

Generally, women tend to use more of Standard English forms than men (Cheshire, 1984, p.43) Yet, Minaj was not at the same point with this theory. Being a famous hip-hop singer, she also interacted with other Black people, who were rappers. During the show, she made quite a lot of non-standard English forms, such as wanna, kinda, throwin', eatin', gotta, gonna, 'bout in which those standard forms are want to, kind of, throwing, eating, got to, going to, about respectively.

This phenomenon also happened when Minaj was in high school. She could not get rid of her Black accent since her British friends enjoyed hearing her speak in her Black accent. This 'encouragement' may have caused Minaj to be more confident with her accent since she realised that she was accepted by her friends the way she was. As a result, 'hypercorrect' grammar disappeared in Nicki Minaj's comments since she often dealt with non-standard English form through her community of practice.

There are also certain ways of speaking which are only acquired from peers and cannot be obtained from parents (Gleason \& Perlmann, 1985, p.93). Minaj mentioned some curse words from her music lyric and she admitted that these curse words were inserted into its lyric purposefully. She seemed to demonstrate that she could not avoid the use of strong swear words in her music career as hiphop music genre was identical to curse words, besides slang words.

\section{Different Social-Psychological Perceptions}

From the theory of social-psychological perceptions from Gleason and Perlmann (1985), it could be considered that Minaj was not able to use language appropriately since her comments were vulgar and not accepted by dominant mainstream. Actually, there was a reason why Minaj inserted those kinds of vulgar comments during the live show. In Minaj's opinion, vulgar or curse words give women chance to not let the stereotype created by men control them (Good, 
2012, p.3). She tried to make the figure of herself as the representative of common women who suffered from too much insecurity. Minaj's different socialpsychological perceptions made her believe that she did not need to use 'superpolite' form and avoid strong swear words in order to suffer from that old stereotype created by men.

\section{Conclusion}

Based on the discussion above, it could be concluded that there were only five features of women's language used by Nicki Minaj in her comments to the contestants of American Idol Season 12. They were intensifier, emphatic stress, filler, rising intonation, and lexical hedge. Meanwhile, the other six features, namely tag question, 'empty' adjective, precise colour terms, 'hypercorrect' grammar, 'superpolite' forms, and avoidance of strong swear words, did not appear in Minaj's comments. The absence of such language features in her comments may be attributed to four out of five possible factors. They were father's speech, ethnicity, community of practice, and different socialpsychological perceptions.

The findings of this research have given some benefits to better understand language use. First, they make people learn "about" language rather than just knowledge "of" language. Mastering a language should make them able to use it for proper and effective communication as language is not only a tool to facilitate communication, but also a means to reflect someone's sex, characteristics and status in society. Second, they demonstrate that general ideas about language can be applied in investigations and observations, not only in language tests. Third, such studies shed light on the importance of knowing how language works differently under different contexts. By being able to grasp differences, language users, especially language learners, are made more open-minded and wiser in dealing with various perceptions towards language. Further research is encouraged with more data sources to enrich the findings and strengthen the claims.

\section{References}

Cheshire, J. (1984). The relationship between language and sex in English. In Trudgill, P. (Ed.), Applied Sociolinguistics. London: Academic Press.

Edwards, J. (1985). Language, society and identity. Oxford: Basil Blackwell.

Engle, M. (1979). Do fathers speak motherese? An analysis of the language development of young children. In Giles, H., \& St. Clair, R. N. (Eds.), Recent advances in language, communication, and social psychology. London: Lawrence Erlbaum Associates Ltd.

Gleason, J. B., \& Perlmann, R. Y. (1985). Acquring social variation in speech. In Giles, H., \& St. Clair, R. N. (Eds.), Recent advances in language, communication, and social psychology. London: Lawrence Erlbaum Associates Ltd.

Good, D. (2012). Nicki Minaj biography: More than a rap artist [Electronic version]. New York: Barnes \& Noble, Inc.

Holloway, L. (2012). Nicki Minaj: The woman who stole the world [Electronic version]. Pheonix: Amber Communications Group, Inc. 
Holmes, J. (2008). An introduction to sociolinguistics ( $3^{\text {rd }}$ ed.). Essex: Pearson Education Limited.

Kress, G. \& Hodge, R. (1979). Language as ideology. In Trudgill, P. (Ed.), Applied sociolinguistics. London: Academic Press.

Lakoff, R. (2004). Language and woman's place: Text and commentaries (M. Bucholtz, Ed.). New York: Oxford University Press, Inc.

Wardaugh, R. (2006). An introduction to sociolinguistics $\left(5^{\text {th }}\right.$ ed.). Oxford: Blackwell Publishing Ltd. 